\title{
Sistem Informasi Kemahasiswaan Politeknik Harapan Bersama (SIKEMAS)
}

\author{
Arif Rakhman ${ }^{1}$, Abdul Basit ${ }^{2}$, Rivaldo Mersis Brilianto ${ }^{2}$ \\ email: cakrakirana7@gmail.com, elangputih@gmail.com, rivaldom@gmail.com \\ Politeknik Harapan Bersama Tegal
}

\begin{abstract}
Abstrak
Mahasiswa menjadi elemen yang sangat penting pada suatu perguruan tinggi khususnya di Prodi D-3 Teknik Komputer Politeknik Harapan Bersama. Politeknik Harapan Bersama merupakan pendidikan vokasi yang terletak di Kota Tegal, jumlah mahasiswa di perguruan tinggi ini mencapai +4000 mahasiswa dan tenaga pendidik serta tenaga kependidikan yang tidak sedikit terdiri dari berbagai program studi. Program studi DIII Teknik komputer adalah Prodi yang mempunyai peserta didik yang cukup banyak yaitu semester dua 302, semester empat 368 dan semester enam 699 dan total seluruh angkatan 1067. Sistem informasi mahasiswa ini di beri nama SIKEMAS (sistem Informasi Kemahasiswaan agar mudah di ucapkan dan familiar bagi pengguna. SIKEMAS menggambarkan interaksi antara pengguna dan sistem, yang setiap pengguna bebas mengakses informasi yang berbeda sesuai ketentuan yang bertujuan agar mahasiswa mendapatkan informasi secara cepat, seperti informasi mengenai aktif studi, cuti studi, prestasi mahasiswa, mahasiswa bermasalah karena melakukan beberapa kali pelanggaran hingga himpunan mahasiswa Prodi. Oleh sebab itu, penelitian ini bertujuan membangun sistem informasi kemahasiswaan untuk Prodi D-3 Teknik Komputer dengan menggunakan metode waterfall. Kumpulan Data yang digunakan adalah metode observasi dan wawancara. Software yang digunakan untuk membangun sistem ini adalah UML dengan Enterprise arsitec untuk perancangan sistem, Bahasa pemrograman yang digunakan adalah PHP dengan framework Code igniter, dan database MySQL. Sistem ini di harapkan bisa mempercepat dan mempermudah proses dalam mendata mahasiswa dari mulai mahasiswa berprestasi hingga yang bermasalah agar Riwayat mahasiswa selama perkuliahan bisa tersimpan dengan baik.
\end{abstract}

Kata kunci : Student interest, Sistem Informasi, UML, PHP, CI, MySQL

\section{Pendahuluan}

Politeknik Harapan Bersama merupakan pendidikan vokasi yang terletak di Kota Tegal, jumlah mahasiswa di perguruan tinggi ini mencapai +4000 mahasiswa dan tenaga pendidik serta tenaga kependidikan yang tidak sedikit terdiri dari berbagai program studi. Program studi DIII Teknik komputer adalah Prodi yang mempunyai peserta didik yang cukup banyak yaitu semester dua 302, semester empat 368 dan semester enam 699 dan total seluruh angkatan 1067.

Koordinator kemahasiswaan adalah elemen penting dalam sebuah program studi dalam me manajemen semua kegiatan dan kebutuhan mahasiswa saat perkuliahan, proses seperti cuti studi, pelanggaran mahasiswa dan pemetaan mahasiswa berprestasi hingga mengelola Himpunan Mahasiswa Program Studi secara administrasi dan secara organisasi.

Banyaknya jumlah mahasiswa menjadi kendala dalam proses pendataan mahasiswa seperti pendataan mahasiswa cuti sudi dan aktif studi, mahasiswa berprestasi dan mahasiswa bermasalah yang melakukan beberapa pelanggaran, dan pendataan organisasi mahasiswa yang ada di lingkungan Prodi DIII Teknik Komputer.
Sistem informasi kemahasiswaan di rancang untuk proses pendataan mahasiswa dari mulai prosedur mahasiswa cuti dan aktif studi, hingga proses pendataan mahasiswa melakukan pelanggaran dan data mahasiswa berprestasi ataupun yang mengikuti organisasi kampus. diharapkan bisa mempercepat dan mempermudah proses dalam mendata mahasiswa dari mulai mahasiswa berprestasi hingga yang bermasalah agar histori dan pendataan mahasiswa bisa direkap dengan baik.

Permasalahan yang terjadi saat ini pencatatan kegiatan kemahasiswaan dan penggunaan ruangan masih dilakukan secara manual dengan menggunakan papan tulis. Sering kali kegiatan tersebut dilaksanakan seiring dengan jadwal perkuliahan sehingga terjadi kendala penggunaan ruangan kegiatan. Hasil dari penelitian ini adalah sebuah aplikasi yang dapat memberikan kemudahan dalam mengelola kegiatan dan penggunaan ruangan serta memudahkan mahasiswa untuk mendapatkan informasi kegiatan kemahasiswaan di kampus.

\section{Metode Penelitian}

Metode yang digunakan adalah Waterfall, Kerangka penelitian ini seperti 
terlihat pada gambar 1 dimana penelitian ini melihat permasalahan yang terjadi di Prodi D3 Teknik Komputer.

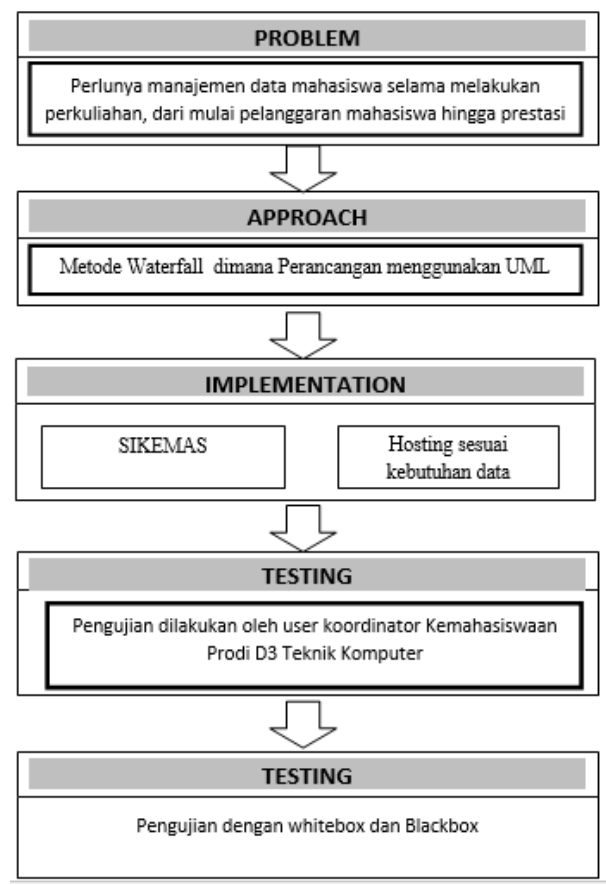

Gambar 1. Kerangka penelitian

Setiap mahasiswa punya data di kemahasiswaan seperti data diri, data pelanggaran dan prestasi mahasiswa serta data mahasiswa yang mengikuti organisasi, dengan jumlah mahasiswa Prodi yang cukup banyak akan banyak kendala untuk proses rekap atau manajemen data mahasiswa tersebut sehingga perlu adanya sistem untuk bisa memanajemeni data mahasiswa agar tersimpan degan baik.

Untuk mendapatkan data yang benarbenar akurat, relevan, valid dan reliable maka pengumpulan data dilakukan dengan cara :

1) Sumber Data Primer

Adalah data yang diperoleh secara langsung dari objek penelitian, baik melalui pengamatan maupun pencatatan terhadap obyek penelitian. Meliputi :

a. Observasi

Pengumpulan data melalui pengamatan dan pencatatan alur dari pengajuan cuti dan aktif studi, serta proses rekap data mahasiswa yang bermasalah, mahasiswa berprestasi hingga mahasiswa yg mengikuti berbagai organisasi dan UKM kampus di program studi D3 Teknik Komputer Politeknik Harapan Bersama. b. Wawancara

Pengumpulan data melalui tatap muka dan tanya jawab langsung dengan sumber data atau pihak-pihak yang berkepentingan yang berhubungan dengan penelitian, misalnya Koordinator Kemahasiswaan koordinator akademik, hingga admin Prodi.

2) Sumber Data Sekunder

Adalah data yang diambil dari buku-buku, dokumentasi, dan literaturliteratur, Meliputi:

a. Studi Kepustakaan

Pengumpulan data dari jurnal dan buku-buku yang sesuai dengan tema permasalahan,

b. Studi Dokumentasi

Pengumpulan data dari literaturliteratur dan dokumentasi dari, diktat, dan sumber informasi lain

\section{Hasil dan Pembahasan}

Penelitian ini membangun sistem menejemen data mahasiswa sesuai dengan kebutuhan user yaitu Prodi D-3 Teknik Komputer terutama koordinator kemahasiswaan untuk efisiensi dalam menejemen data mahasiswa cuti studi, aktif studi, mahasiswa bermasalah, prestasi mahasiswa dan organisasi mahasiswa agar data tersimpan dengan baik dan aman.

Jumlah mahasiswa Prodi D3 Teknik Komputer Tahun Akademik 2020/2021 Genap sekitar 1067 seluruh angkatan terdiri dari semester dua 302, semester empat 368 dan semester enam 699. Dari data mahasiswa tersebut terdiri dari beberapa data mahasiswa seperti:

Tabel 1. Jumlah Mahasiswa Prodi Komputer

\begin{tabular}{|l|l|}
\hline Nama data & Jumlah data \\
\hline $\begin{array}{l}\text { Pelanggaran } \\
\text { mahasiswa }\end{array}$ & $\begin{array}{l}\text { 50 jumlah } \\
\text { pelanggaran }\end{array}$ \\
\hline Prestasi & $\begin{array}{l}12 \text { mahasiswa } \\
\text { berprestasi }\end{array}$ \\
\hline Berorganisasi & $\begin{array}{l}12 \text { mahasiswa } \\
\text { berprestasi }\end{array}$ \\
\hline Mahasiswa cuti studi & 32 mahasiswa \\
\hline
\end{tabular}

Data pelanggaran dengan beberapa jenis pelanggaran seperti keterlambatan mengsisi KRS (Kartu Rencana Studi) pelanggaran dalam perkuliahan, dan pelanggaran yang lain.

Ada 12 mahasiswa yang terdata oleh prodi dengan berbagai prestasi dengan bidang yang berbeda-beda dan kompetensi mahasiswa 
seperti bidang kompetensi prodinya yaitu Teknik Komputer, olahraga, seni, game dan lain-lain.

Mahasiswa yang mengikuti organi sasi sekitar 27 mahasiswa yang terbagi menjadi beberapa organisasi seperti BPM (Badan Pengawas Mahasiswa), BEM (Badan Eksekutif Mahasiswa) HIMA PRODI (Himpunan Mahasiswa Prodi) dan UKM.

Data mahasiswa yang cuti dan di cuti kan ada 32 Mahasiswa yang terdiri dari semester 1, 3 dan 5, data ini di ambil Ketika akan dilaksanakannya tahun akademik 2020/2021 Genap.

Sistem ini di beri nama SIKEMAS (Sistem informasi kemahasiswaan) untuk mempermudah dalam penyebutan dan penamaan di domain. Berdasarkan hasil pengumpulan data-data yang diperlukan, maka ditentukan domain dari website ini adalah https://sikemas.d3komputerphb.id/.

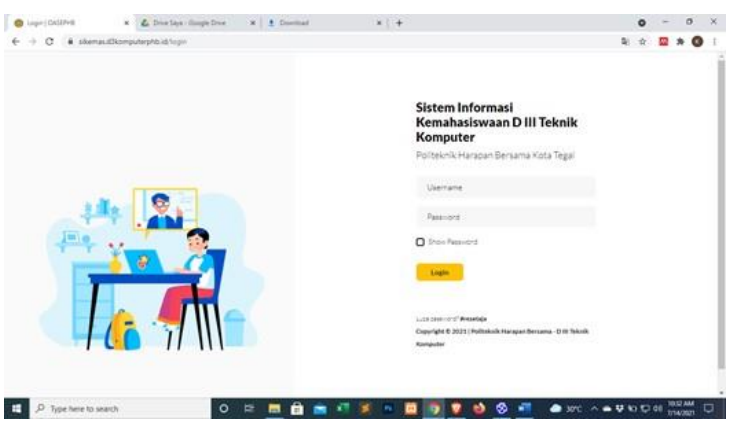

Gambar 2. Login SIKEMAS

Pada menu ini Super admin, Admin dan Mahasiswa melakukan login dengan username yang sudah di tentukan untuk super admin, admin, dan untuk mahasiswa dengan mengisikan nim, dimana password awal adalah nim mahasiswa dan user dapat mengganti password setelah masuk pertama kali. Jika telah selesai menggungah atau melakukan kegiatan pada SIIKEMAS maka user dapat logout.

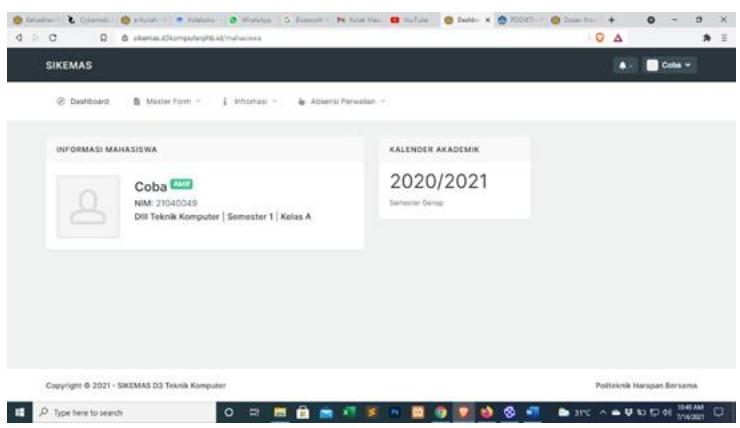

Gambar 3. Menu dashboard mahasiswa
Menu ini hannya berisi data diri mahasiswa dan tahun akademik yang sedang dijalani mahasiswa.

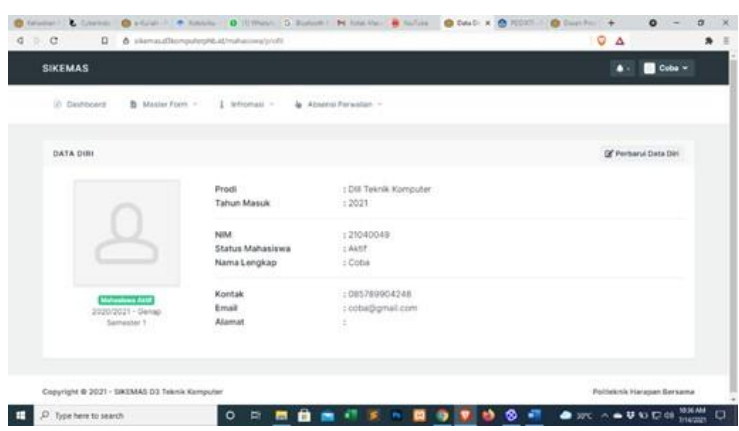

Gambar 4. Tampilan menu profile mahasiswa

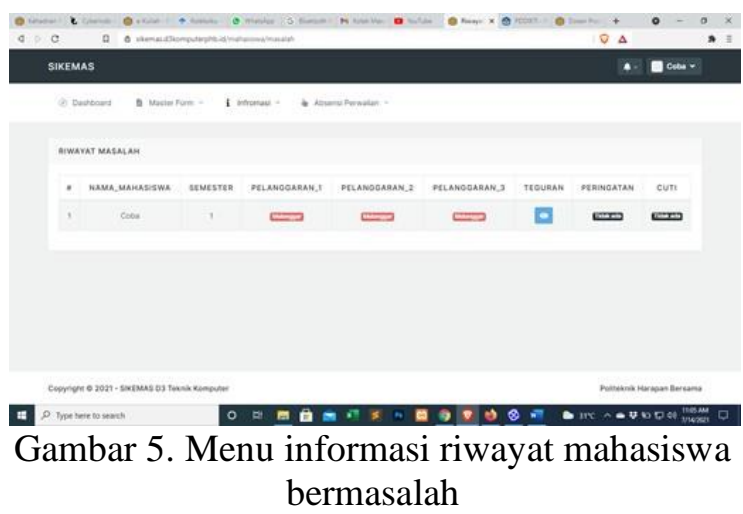

Menu ini berisi mengenai Pelanggaran yang pernah dilakukan mahasiswa selama melakkan perkuliahan di prodi D3 Teknik Komputer, pelanggaran ini berlevel sampai jika mahasiswa melakukan beberapa kesalahan.

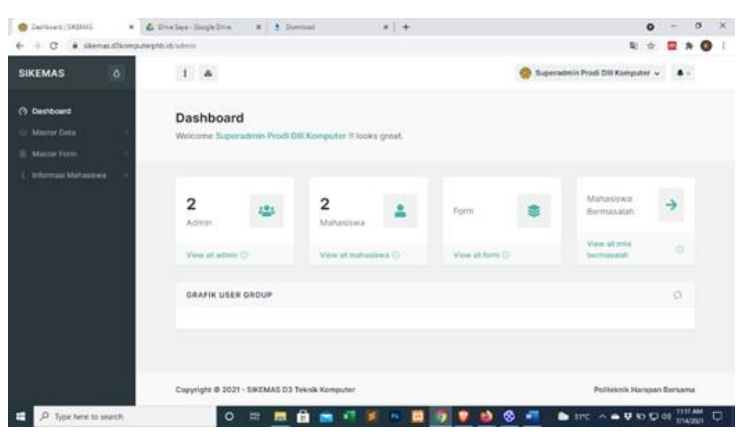

Gambar 6. Menu dashboard

Menu ini berisi mengenai semua menu yang ada di sistem ini dengan indicator jumlah data yang ada di menu masing-masing. 


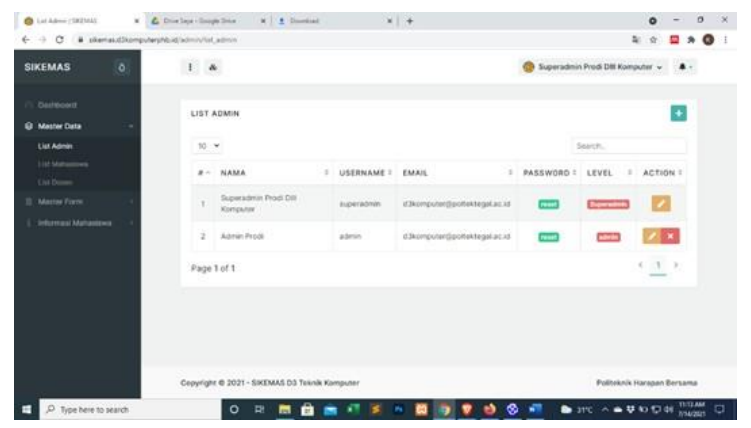

Gambar 7. Menu list admin

Menu ini menampilkan data semua user yang berada di sistem ini dari super admin dan admin.

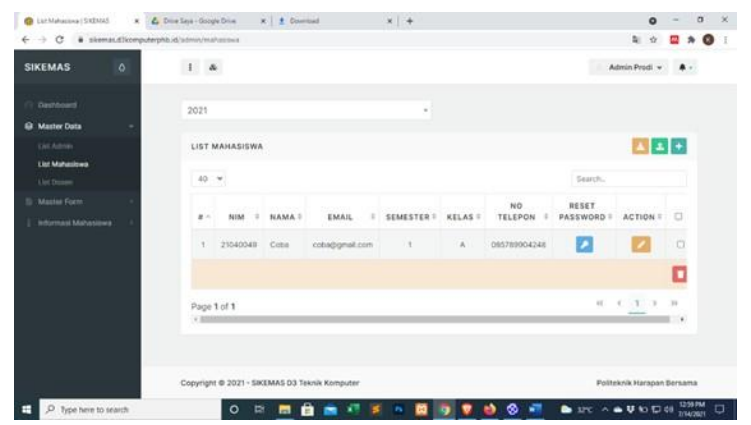

Gambar 8. Menu list mahasiswa

Menu list untuk semua data mahasiswa prodi D-3 Teknik computer menu ini juga di fungsikan untuk mereset paswrod dan update data mahasiswa. Disini juga admin dan superadmin dapat menginput data satu per satu dari data user, atau memasukkan data dengan cara import dan exportdata dalam bentuk file excel.

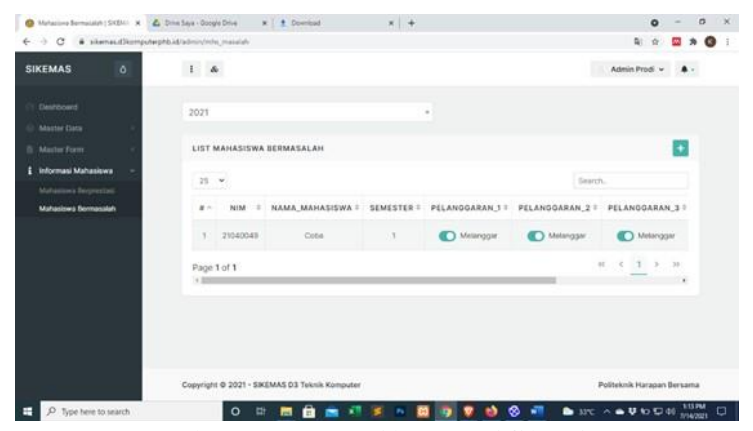

Gambar 9. Tampilan verifikasi

Menu ini berisi mengenai data mahasiswa yang akan di berikan status melakukan pelanggaran dengan berlevel, muali dari pelanggaran ke satu sampe tiga setelah itu baru di berikan surat teguran, level selanjutnya surat peringatan, dan opsi terakhir adalah surat cuti.

\section{Kesimpulan}

Penelitian ini dilakukan karna terkendalanya sistem administrasi menejemen data mahasiswa di kemahasiswaan prodi D-3 Teknik Komputer Politeknik Harapan Bersama dengan beberapa aspek yang di pertimbangkan melakukan analisa proses yang berjalan, perancangan sistem yang dikembangkan sampai ke tahapan pengujian terhadap sistem ini, maka ditarik kesimpulan:

1. Pengimplementasian sistem ini di harapkan dapat memudahkan Prodi D-3 Teknik Komputer dalam memanajemen data kemahasiswaan lebih efektif dan data tersimpan dengan baik dan aman.

2. Mempermudah memberikan informasi kepada mahasiswa mengenai data kemahasiswaan atau kebutuhan dibidang kemahasiswaan saat perkulihan.

\section{Daftar Pustaka}

[1]I. M. A. Pradnyana and N. Sugihartini, "Analisis dan Perancangan Sistem Informasi Pendukung Data Kemahasiswaan," Semin. Nas. Vokasi dan Teknol., pp. 296-306, 2016.

[2] T. Abidin and S. Wiyono, "Rancang Bangun Sistem Informasi Kemahasiswaan (Studi Kasus: Program Studi D IV Teknik Informatika Politeknik Harapan Bersama Tegal)," J. Inform. Pengemb. IT, vol. 2, no. 1, pp. 30-36, 2017.

[3] S. H. Mulyani, "Rancang Bangun Sistem Informasi Sistem Kredit Partisipasi Aktivitas Mahasiswa (Siskpam)," J. Sist. Inf., vol. 8, no. 2, pp. 1069-1079, 2016, [Online]. Available: http://ejournal.unsri.ac.id/index.php/jsi/inde $\mathrm{x}$.

[4]A. J. Oktasari and D. Kurniadi, "Perancangan Sistem Informasi Manajemen Kegiatan Mahasiswa Berbasis Web," J. Vokasional Tek. Elektron. dan Inform., vol. 7, no. 4, pp. 150-157, 2019.

[5]N. L. W. S. R. Ginantra and K. J. Atmaja, "Aplikasi Manajemen Kegiatan Kemahasiswaan Stiki Indonesia Berbasis Web," J. Ilm. Teknol. Inf. Asia, vol. 12, no. 1, p. 1, 2018, doi: 10.32815/jitika.v12i1.209.

[6]F. Ilmu et al., "BERBASIS WEB DAN SMS GATEWAY Fakultas Ilmu Komputer dan Manajemen - Universitas Sains dan Teknologi Jayapura," vol. 6, no. 1, pp. 1-8, 2018. 